\title{
Diabetic Peripheral Neuropathies: A Morphometric Overview
}

\author{
Neuropatías Diabéticas Periféricas: Una Visión General Morfométrica
}

\author{
*,*** Valéria Paula Sassoli Fazan; ${ }^{*, * * *, * * * *}$ Carlos Augusto Carvalho de Vasconcelos; \\ ${ }^{* * * * *}$ Marcelo Moraes Valença; * Randy Nessler \& *Kenneth Charles Moore
}

FAZAN, S. V. P.; DE VASCONCElOS, C. C. A.; VAlenÇA, M. M.; NESSLER, R. \& MOORE, K. C. Diabetic peripheral neuropathies: a morphometric overview. Int. J. Morphol., 28(1):51-64, 2010.

SUMMARY: Diabetes is now considered one of the main threats to human health in the 21 st century and many researchers are dedicated to investigate the physiopathology of the disease, with further insights on the managements of its major complications. Since understanding the pathophysiology of the major complications of diabetes and their underlying processes is mandatory, experimental models of the disease may be useful as they allow the recognition of the early mechanisms involved in the long-term complications of diabetes. Peripheral nerve involvement is highly frequent in diabetes mellitus and it has been documented that one third of diabetic patients have peripheral neuropathy. The true prevalence is not known and reports vary from $10 \%$ to $90 \%$ in diabetic patients, depending on the criteria and methods used to define neuropathy. In this review, the most common experimental models of diabetes are presented and the pathological findings on major peripheral nerves are discussed. Also, the insights brought by morphometry to the diabetic neuropathy research are highlighted.

KEY WORDS: Diabetes; Experimental models; Neuropathy; Morphometry.

\section{Epidemiological and Public Health Problems Associated to Diabetes}

Diabetes mellitus coupled with cardiovascular disorders are the most challenging public health problems worldwide. Diabetes is now considered one of the main threats to human health in the $21^{\text {st }}$ century (Zimmet et al., 2001). Its epidemiology is changing basically due to changes in human behavior and life style, which resulted in a dramatic increase in the incidence of diabetes in the last decade, especially in South America, Africa and East Asia (of 44, 50 and $57 \%$ respectively) (Zimmet et al.). There are two well known types of diabetes. Type 1 diabetes, formerly labeled "juvenile-onset diabetes" is due to an autoimmune-mediated destruction of pancreatic beta-cells resulting in insulin deficiency. Its pathogenesis involves environmental triggers that may activate autoimmune mechanisms in genetically susceptible individuals. Predisposition is mediated by a number of genes that interact in a complex manner with each other and the environment (Zimmet et al.). Type 2 diabetes formerly labeled "maturity-onset diabetes" is characterized by insulin resistance or an abnormal secretion of insulin.
This is a multifactorial disease and there can be a relationship with other metabolic disorders such as impaired glucose tolerance and impaired fasting glucose (Zimmet et al.). These two types of diabetes do not carry with them any implications of the age of onset of either condition (Williams \& Airey, 2002). Most diabetic epidemic reports deal with type 2 diabetes because the type 1 frequency is low relatively to type 2 , which accounts for over $90 \%$ of cases globally (Zimmet et al.).

In accordance to the latest International Diabetes Federation (IDF) publication (International Diabetes Federation), it is clear that the incidence and prevalence of diabetes are increasing at an alarming rate both in developed and in developing countries but the largest proportional and absolute increase will occur in developing countries, particularly India and China. In 2003, world diabetes prevalence in adults ( $20-79$ years) was $5.1 \%$ in a population of 3.8 billion. The highest prevalence of diabetes in the adult population is in North America (7.9\%), Europe (7.8\%) and South America's prevalence is $5.6 \%$. The number of deaths attributed to diabetes in adults is above 300,000 males in

Central Microscopy Research Facility, The University of Iowa, 85 Eckstein Medical Research Building, Iowa City, IA, 52241, USA.

** Department of Surgery and Anatomy, School of Medicine of Ribeirão Preto, University of São Paulo, Ribeirão Preto, SP, Brazil.

*** Laboratory of Immunopathology Keizo Asami (LIKA), Electron Microscopy Section, Federal University of Pernambuco, Recife, PE, Brazil.

***** Department of Neuropsychiatry, Division of Neurology and Neurosurgery, Federal University of Pernambuco, Recife, PE, 50670-901, Brazil. 
Europe, East-Asia and Western Pacific and above 400,000 females in the same regions.

There is a clear connection between type 2 diabetes and population weight gain. Childhood obesity is a relatively recent phenomenon and it poses a critical threat to health. Overweight and obesity affects one in 10 children worldwide, but the rate is double in Europe and three times as great across the Americas. The emergence of type 2 diabetes in childhood is a serious development. In the USA, up to $45 \%$ of children with newly diagnosed diabetes have type 2 diabetes and most are overweight or obese at diagnosis.

In recent years, it is clear that the major problem of diabetes is not treating the acute life-threatening hyperglicaemia but the prevention, treatment and rehabilitation of the long-term complications of diabetes. In this regard, understanding the pathophysiology of the major complications of diabetes and their underlying processes is critical. Thus, experimental models of the disease will allow the recognition of the early mechanisms involved in the longterm complications of the disease.

The complications of diabetes may be classified into those from atherosclerosis (cardiovascular, cerebrovascular and peripheral vascular) and from other mechanisms. Retinopathy, nephropathy and neuropathy occur in both types of diabetes (Dyck \& Giannini, 1996). Neuropathy is a common complication of diabetes that accounts for a significant high morbidity. Sensory loss of the lower limbs may cause foot ulceration that can lead to lower extremity amputation. Indeed, it has been reported that $20 \%$ of all hospital admissions among diabetic patients in the USA are for foot problems and the rate of lower limb amputation is 15 times higher in diabetic than in non-diabetic patients.

\section{Diabetic Neuropathy}

Peripheral nerve involvement is highly frequent in diabetes mellitus and it has been documented that one third of diabetic patients have peripheral neuropathy (Comi \& Corbo, 1998). The true prevalence is not known and reports vary from $10 \%$ to $90 \%$ in diabetic patients depending on the criteria and methods used to define neuropathy (Vinik \& Mehrabyan, 2004). The close correlation between hyperglicaemia and the development of a clinically detectable neuropathy has been well documented in many studies and risk factors for the neuropathy development have been suggested such as high cholesterol levels, smoking, hypertension, male sex, older age and poor glycaemic control (Comi \& Corbo; Harati, 2007). Diabetic neuropathy is an heterogeneous disorder (Harati, 1987; Comi \& Corbo; Vinik et al., 2000) with high morbidity and can be classified as a number of different syndromes ranging from sub-clinical to clinical manifestations, depending on the classes of fibers involved (Vinik \& Mehrabyan, 2004). It is the most common form of neuropathy in developed countries (Vinik et al., 2000 ) and at least $50 \%$ of diabetic patients develop one or several forms of diabetic neuropathies within 25 years after diagnosis (Harati, 1987). Diabetic neuropathy encompasses a wide range of abnormalities affecting proximal and distal peripheral sensory as well as motor nerves and the autonomic nervous system (Vinik et al., 2000). Distal symmetric sensory or sensorimotor polyneuropathy with a variable degree of autonomic involvement is the most common type of diabetic neuropathy (Comi \& Corbo; Vinik \& Mehrabyan).

Clinical manifestations of the symmetric distal polyneuropathies differ depending on the nerve fiber type most involved. In predominantly small-fiber type neuropathy, pain and paresthesias, most commonly in the lower extremities, are characteristic symptoms. Nevertheless, it is an electrophysiologically silent condition. Recently, there is evidence that this condition may be accompanied by loss of cutaneous nerve fibers that stain positive for the neuronal antigen PGP 9.5 (Vinik \& Mehrabyan). Autonomic dysfunction is more prevalent in this form of neuropathy.

In the predominantly large-fiber type symmetric polyneuropathies, loss of ankle reflexes, decreased position and vibratory senses and sensory ataxia are present (Harati, 1987). Large-fiber neuropathies may involve sensory or motor nerves. These tend to be the neuropathies of signs rather than symptoms because large fibers subserve motor function, vibration perception, position sense and cold thermal perception. Unlike the small fibers, these are the myelinated, fast conducting fibers that begin in the toes and have their first synapse in the medulla. They tend to be affected first because of their length and the tendency in diabetes for nerves to "die back" (Vinik \& Mehrabyan). Although sensory disturbances predominate in diabetic polyneuropathy, distal muscle weakness in the lower limbs may be present, usually in advanced cases, and is believed to be related to the neurogenic atrophy caused by motor axon degeneration (Comi \& Corbo).

Progression of diabetic neuropathy is related to glycaemic control in both type 1 and type 2 diabetes (Vinik et al., 2000; Vinik \& Mehrabyan). Retrospective and prospective studies have suggested a relationship between hyperglycemia and the development and severity of diabetic neuropathy (Vinik \& Mehrabyan). The duration of diabetes and degree of metabolic control are the two major predictors of the development of neuropathy and determinant of its severity (Harati, 2007). Despite the differences in causation of both types of diabetes, it has traditionally been assumed 
Table 1: Most common abnormalities implicated in the pathogenesis of diabetic neuropathy according to the two major proposed sub-groups

\section{Vascular Etiology \\ Metabolic Etiology}

Hyperglycemia

$\uparrow$ Endoneural vascular resistance

$\downarrow$ Nerve blood flow (endoneural hypoxia)

Endothelial dysfunction $(\downarrow$ prostacyclin and nitric oxide, $\uparrow$

endothelin)

Advanced glycation of vessel wall

Basement membrane thickening

Endothelial cell swelling and pericyte degeneration

Closed (collapsed) capillaries

Occlusive platelet thrombi

Epineural vessel atherosclerosis

$\uparrow$ Oxygen free radicals activity
Hyperglycemia / Hypoinsulinemia

Dyslipidaemia

$\uparrow$ Aldose reductase activity $(\uparrow$ polyols,

$\downarrow$ myo-inositol)

$\downarrow$ Nerve sodium-potassium ATP-ase

$\downarrow$ Rate of synthesis and transport of intra-axonal proteins

$\uparrow$ Glycogen accumulation

$\uparrow$ Monoenzymatic peripheral nerve protein glycosylation

$\downarrow$ Incorporation into myelin of glycolipids and aminoacids

Abnormal inositol lipid methabolism

$\downarrow$ Nerve L-carnitine level

$\uparrow$ Protein kinase C activity that the neuropathy of types 1 and 2 diabetes is the consequence of hyperglycemia and the same patogenetic factors (Harati, 2007).

Diabetic autonomic neuropathy is among the least recognized and understood complications of diabetes despite its significant negative impact on survival and quality of life (Vinik et al., 2003). Little is known about the epidemiology of the autonomic neuropathy in the different types of diabetes (Comi \& Corbo) and much remains to be learned about the natural course of diabetic autonomic neuropathy (Vinik et al., 2000). Dysfunction of the autonomic nervous system is seen in approximately 20 to $40 \%$ of diabetics and it is not simply an "all or none" phenomenon (Harati, 1987). Diabetic autonomic neuropathy typically occurs as a system-wide disorder affecting all parts of the autonomic nervous system. Indeed, because the vagus nerve (the longest of the autonomic nerves) accounts for $\sim 75 \%$ of all parasympathetic activity, and diabetic neuropathy manifests first in longer nerves, the symptoms of even early autonomic neuropathy are widespread (Vinik et al., 2003).

Despite recent information about pathogenetic mechanisms for many of the long term complications of diabetes, the exact pathogenesis of diabetic neuropathy remains unknown. Several hypotheses have been proposed to explain pathogenesis of diabetic polyneuropathy, but the real cause is not well understood. Different mechanisms for the pathogenesis have been described but none has achieved general acceptance. They are divided into two major subgroups: abnormalities that suggest a metabolic etiology and abnormalities that suggest a vascular etiology. Table 1 summarizes the hypothesis implicated in the pathogenesis of diabetic neuropathy. For most, there is strong experimental support but the details of each mechanism and their possible interrelationships remain unanswered (Harati, 2007). It seems that the formation of advanced glycation end products may be an unifying bridge between the two 
major hypothesis since it explains many of the diabetic complications (Harati, 2007). In terms of peripheral neuropathy, the protein glycation cascade suggested by Harati (Harati, 2007) may lead either to demyelination or axonal atrophy. In the first case, glycation of the myelin proteins would account for myelin destruction and consequent demyelination. On the other hand, glycation of collagen and laminin could lead to a reduction in nerve growth factor, leading to axonal atrophy. It is possible that interactions between several direct and indirect metabolic consequences of insulin deficiency, hyperglycemia, as well as genetic and environmental factors are required for the mergence of diabetic neuropathies (Harati, 1987).

Four main reasons for studying the pathological alterations of the diabetic neuropathy were clearly pointed out by Dyck \& Giannini: 1) to characterize the interstitial pathologic alterations of nerve that cannot be inferred from clinical or electrophysiological studies; 2) to infer mechanisms and causes; 3) to correlate morphometric abnormalities with change in clinical impairment and nerve conduction, quantitative sensory testing and quantitative autonomic testing abnormalities; and 4) to correlate neuropathological findings with metabolic derangements.

\section{Experimental Models of Diabetes}

Experimental models of diabetes can be divided into two main categories: genetic (spontaneous) and induced syndromes. Many different mammalian species can be used as experimental models of diabetes including monkeys, cats, sheep, rabbits, dogs, pigs, hamsters, guinea pigs, rats and mice. Nevertheless, due to their relatively small size, reduced cost, easy to bread in and maintenance in animal care facilities, rats are the most common animals used in the experimental diabetes investigations. However, the use of mouse models to advance knowledge of physiology, pathology and development is exploding in all areas (Fazan et al., 2002), mainly due to the availability of genetically manipulated mice. Thus, mice are being introduced as another rodent model for experimental neuropathies studies.

Alloxan and streptozotocin (STZ) are the most prominent diabetogenic chemicals used to induce experimental diabetes in animals (Szkudelski, 2001; Lenzen, 2008). Since both are cytotoxic to pancreatic beta-cells, their use to introduce experimental diabetes in rats is convenient and simple.

Diabetic-inducing property of alloxan was first identified in 1943 (Dunn \& McLetchie, 1943) as a result of the observed specific necrosis of pancreatic beta-cells (Dunn et al., 1943). Alloxan diabetes (state of experimental diabetes resulting in insulinopenia after the alloxan injection) was then successfully induced in rabbits (Bailey \& Bailey, 1943), rats (Dunn \& McLetchie; Gomori \& Goldner, 1943), dogs (Lukens, 1948) and other species such as cats, sheep, monkeys, pigs and mouse (Lazarow, 1947; Lukens). Guinea pigs have shown to be resistant (Johnson, 1950). Subsequent decades witnessed a rise in journal articles reports and reviews about alloxan and its diabetogenic properties (Lazarow, 1949; Rerup, 1970; Rossini et al., 1975; Mordes \& Rossini, 1981; Kurahashi et al., 1993; Szkudelski, 2001; Lenzen). Alloxan is a hydrophilic and unstable substance with a molecular shape resembling glucose. Its half-life at neutral $\mathrm{pH}$ and $37^{\circ} \mathrm{C}$ is about $1.5 \mathrm{~min}$ (Lenzen \& Munday, 1991) but when a diabetogenic dose is used, its time of decomposition is sufficient to allow pancreas penetration in amounts that are deleterious (Szkudelski). Rapid uptake by insulin-secreting cells has been proposed to be one of the important features determining alloxan diabetogenicity. Alloxan exerts its diabetogenic action when administrated intravenously, intraperitoneally or subcutaneously. The dose required for diabetes induction depends on the animal species, route of administration and animal nutritional status, age and gender (Gold et al., 1981). The most frequently used intravenous dose used to induce diabetes in rats is $65 \mathrm{mg} / \mathrm{kg}$ (Gruppuso et al., 1990, Boylan et al., 1992) but the effective dose for intraperitonealy or subcutaneously injections must be 2 to 3 times higher (Szkudelski). Fasted animals are more susceptible to alloxan (Katsumata et al., 1992; Szkudelski et al.) but high blood glucose levels provide partial resistance (Bansal et al., 1980; Szkudelski et al., 1998). Several investigations suggested that the selectivity of alloxan action is not quite satisfactory and alloxan uptake occurs in liver and other tissues (Malaisse et al., 1982; Tiedge et al., 1997).

The diabetogenic property of STZ was observed 20 years later than alloxan (Rakieten et al., 1963) and since then, it has been the agent of choice for the induction of diabetes mellitus in animals (Arison et al., 1967; Lenzen, 2008). STZ is more efficient and specific to the pancreatic beta-cells than alloxan (Rakieten et al., 1963). STZ synthesized by Streptomycetes achromogenes and is used to induce both insulin-dependent and non-insulin-dependent diabetes mellitus (Szkudelski). As with alloxan, its beta-cell specificity is mainly the result of selective cellular uptake and accumulation. The range of the STZ dose is not as narrow as in the case of alloxan and the frequently used single intravenous injection of 40 to $60 \mathrm{mg} / \mathrm{kg}$ in adult rats is enough to induce an insulin-dependent diabetes mellitus state (Ganda et al., 1976; Rodrigues Filho \& Fazan, 2006). If given in multiple low doses, predominantly in the mouse, an induction of an insulin-dependent diabetes mellitus state is achieved by activation of immune mechanisms (Szkudelski). Due to its chemical properties, particularly greater stability, STZ is 

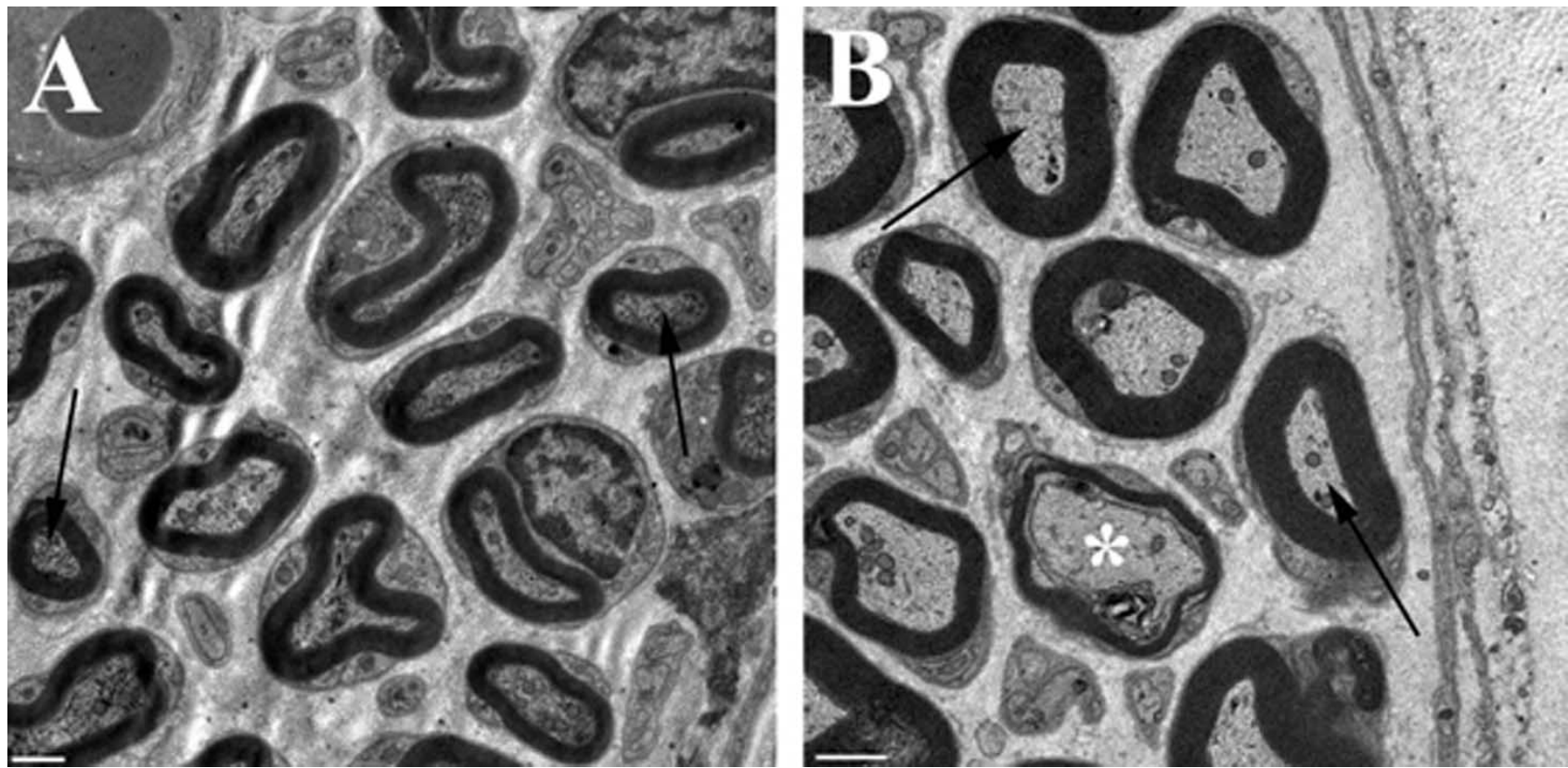

Fig. 1. Representative electron-micrographs of the aortic depressor nerve of chronic STZ-induced diabetic rats showing axonal atrophy (arrows). Note in "B" the presence of an image suggestive of demyelination (*). Scale bar $=1 \mu \mathrm{m}$.
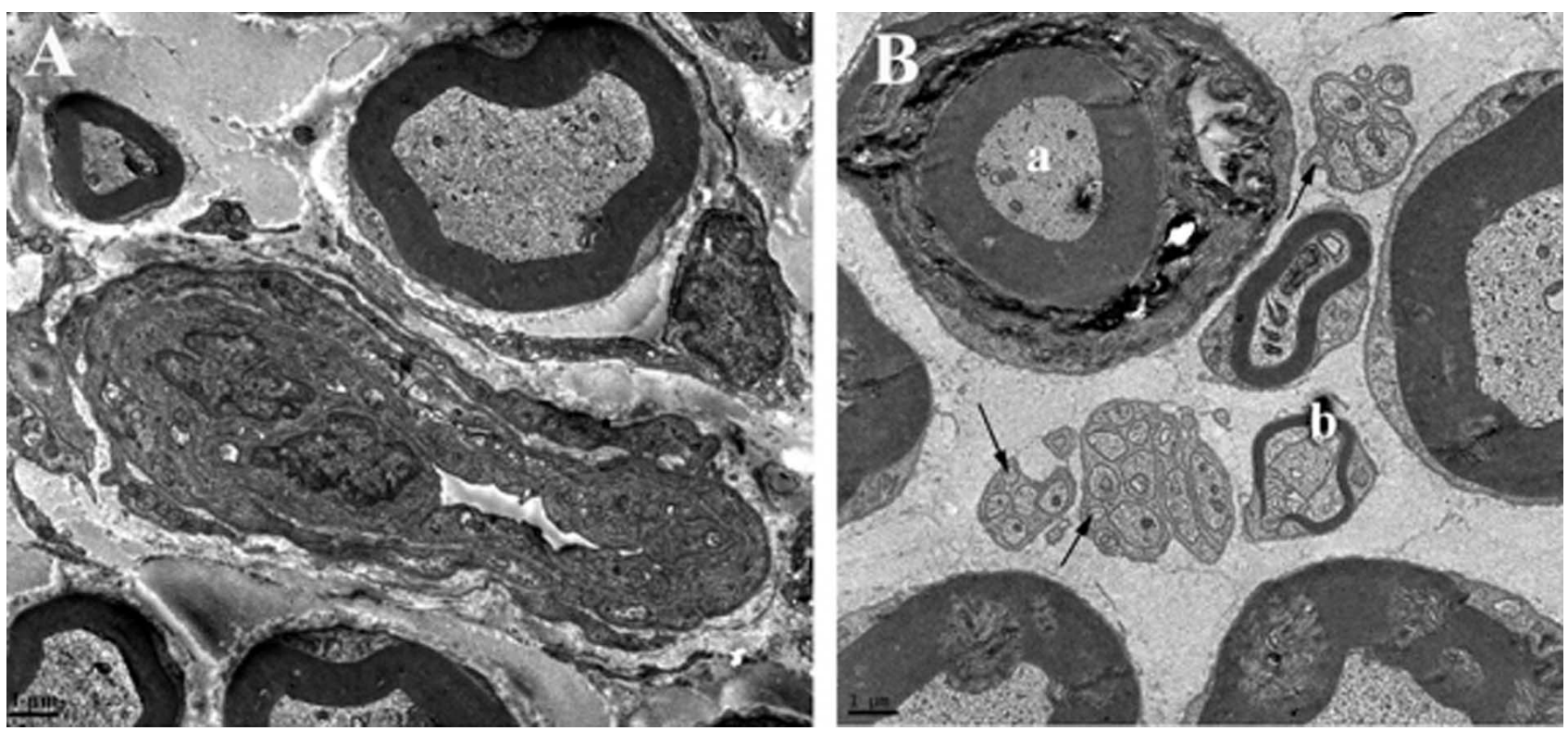

Fig. 2. Representative electron-micrographs of the phrenic nerve of chronic STZ-induced diabetic rats. "A" shows a collapsed endoneural vessel with thickening of the wall. "B" shows a large myelinated fiber (a) with loose myelin sheath and signs of axonal atrophy. Note also, the presence of a small myelinated fiber (b) with a very thin and loose myelin sheath, suggestive of remyelination. Arrowheads point to micro-axons which were very common on the unmyelinated fibers. Scale bar $=1 \mu \mathrm{m}$

the agent of choice for reproducible induction of a diabetic metabolic state in experimental animals (Lenzen, 2008).

Injections of alloxan and STZ induce the same blood glucose, plasma insulin responses and morphological features of pancreatic beta-cells destruction characteristics of necrotic cell death (Lenzen, 2008). When using these chemically induced models of experimental diabetes, one should take into account that this mechanism is clearly at a variance with that which underlies autoimmune type 1 diabetes in humans and rodent models where beta-cell demise is the result of apoptotic cell death (Lenzen, 2008). 

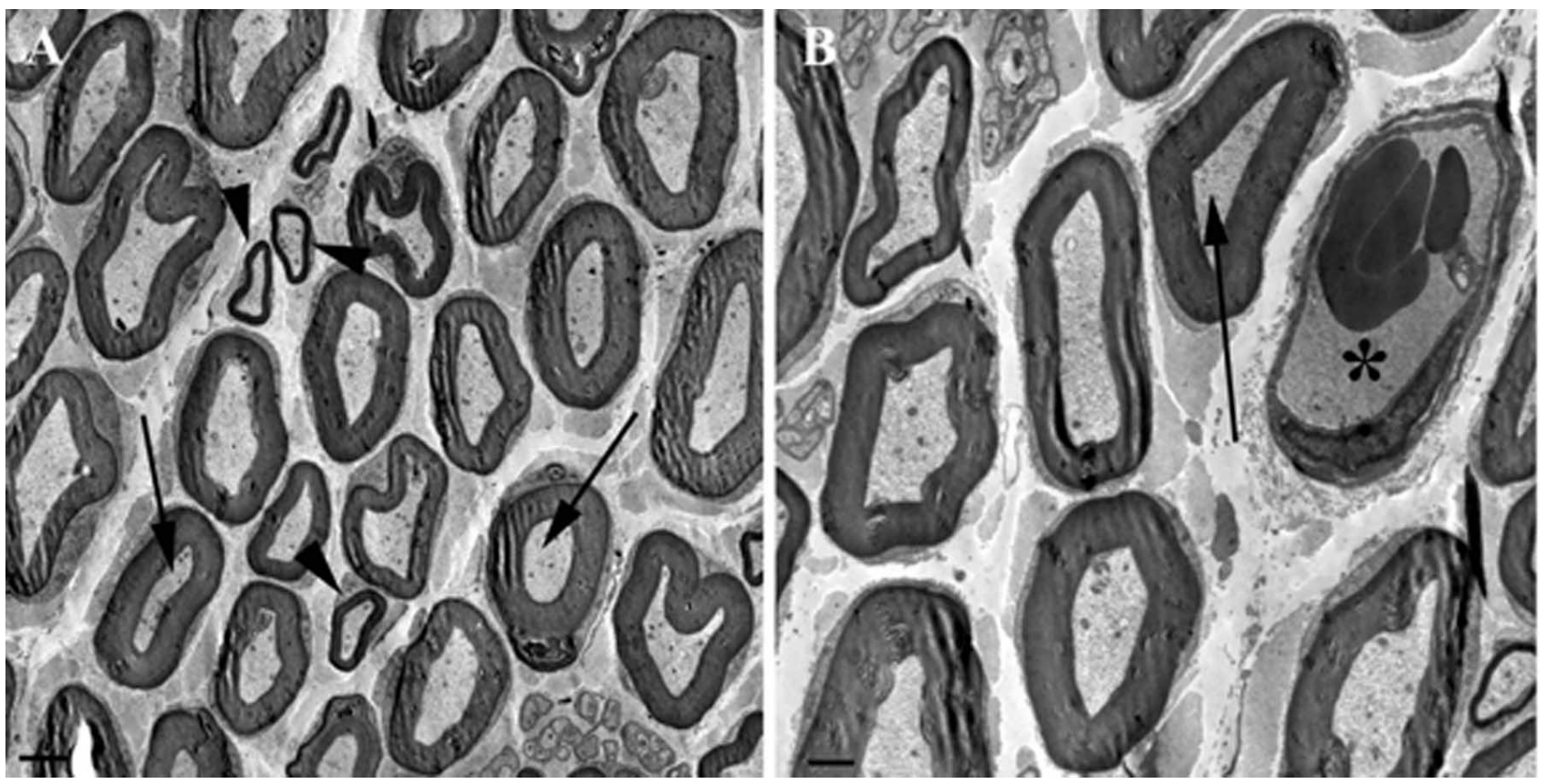

Fig. 3. Representative electron-micrographs of the sciatic nerve of acute STZ-induced diabetic rats. Arrows show axonal atrophy of large myelinated fibers while the small myelinated ones (arrowheads) are normal. In "B", a normal blood vessel is shown (*). Scale bar $=2 \mu \mathrm{m}$ and $=1 \mu \mathrm{m}$ in $\mathrm{A}$ and $\mathrm{B}$, respectively.

The understanding of changes in beta-cells of the pancreas as well as in the whole organism after alloxan or STZ treatment is essential for using these compounds as diabetogenic agents. For a complete review of alloxan and streptozotocin mechanisms of action, refer to Szkudelski and Lenzen.

Some of the most well characterized spontaneous models of experimental diabetes are the Chinese hamster, the $\mathrm{BB} / \mathrm{W}$ rat, the $\mathrm{db}$ mouse, the guinea pig and the Macaca nigra models.

The Chinese hamster was first described in 1959 (Meier \& Yerganian, 1959) and after selective inbreeding, several diabetic lines have been produced. Diabetes in this model is hereditary and characterized by hyperphagia, polydispsia, glycosuria, hyperglycemia and decreased longevity (Sims \& Landau, 1967; Gerritsen \& Dulin, 1967; Gerritsen et al., 1974; Gerritsen \& Blanks, 1974). The hamsters are not obese. After population studies of various diabetic sub-groups, it was proposed that four autosomal recessive genes are involved in inheritance of diabetes in this model (Butler, 1962; Gerritsen et al.).

The spontaneous diabetic BB/Wistar rat was first recognized in 1974 and it is considered a model of type 1 diabetes with a current incidence of diabetes of approximately 40\% (Bell \& Hye, 1983). The diabetic animals are lean, hyperglycemic, hypoinsulinemic and have significant polyuria and glycosuria. Males and females are affected equally. Onset of diabetes is abrupt, early and progressive with ketoacidosis developing in 60 to $80 \%$ of the diabetic animals (Tannenbaum et al., 1981; Nakhouda et al., 1977; Nakhouda et al., 1978). The hyperglycemia is caused by an immune-mediated destruction of insulin producing cells (Harati, 2007). Genetic examination of diabetes in the $\mathrm{BB} / \mathrm{W}$ rat indicates transmission via a single autosomal recessive gene with $50 \%$ phenotypic expression when homozygous for diabetes (Bell \& Hye).

The $\mathrm{db}$ mouse (C57BL/KsJdb) was first reported in 1966 (Hummel et al., 1966) and it presents a syndrome similar to type 2 diabetes in humans characterized by obesity, infertility, hyperphagia and marked hyperglycemia (Hummel et al.; Bray \& York, 1979; Coleman \& Hummel, 1967; Coleman, 1978; Herberg \& Coleman, 1977). Obesity precedes the onset of hyperglycemia. Diabetes in the $\mathrm{db}$ mouse is hereditary and due to a single gene mutation located on chromosome 4 (Bell \& Hye). Homozygous animals are all obese, diabetic and infertile (Coleman, 1982). In contrast to the Chinese hamster and $\mathrm{BB} / \mathrm{W}$ rat, db mice present early hyperinsulinemia that drops to normal levels with aging.

Spontaneous diabetes in the guinea pig is a model of type 1 diabetes, initially reported in 1973 (Munger \& Lang, 1973). They present glycosuria and hyperglycemia that affect 
$50 \%$ of animals in their breeding colony. Only $10 \%$ of animals develop ketoacidosis and insulin treatment is not required (Bell \& Hye). A viral infection is thought to be the etiological agent but none was isolated (Munger \& Lang).

The etiology of the Macaca nigra diabetes is uncertain but resembles type 2 diabetes in humans. This is a useful animal model of diabetes particularly because it is the species most closely related to humans that any other diabetic animal (Bell \& Hye, 1983).

Other models of spontaneous diabetes are available but have been much less explored and their availability is limited. For example, the non-obese diabetic mouse (NODmouse) becomes insulin dependent because of a marked insulinitis (Makino et al., 1980) but spontaneous diabetes develops over a time which may range from 12 to 30 weeks of age and animals with the same duration of diabetes may differ significantly in age (Schmidt et al., 2003). This could introduce bias in the interpretation of morphological findings particularly for the nervous system. The leptin-deficient mouse (ob/ob-mouse) is a model of type 2 diabetes with mild hyperglycemia, insulin resistance and early obesity (Drel et al., 2006). The obese and hyperglycemic BBZ rats serve as a model of type 2 diabetes, with insulin resistance and a slowly progressive nerve conduction deficit (Harati, 2007). For a review of the animal models of diabetes mellitus refer to Mordes \& Rossini; Bell \& Hye; Tarui et al., 1987 and Sharma \& Thomas, 1999.

\section{Experimental Diabetic Neuropathy in Rats: Morphometry Insights}

It has long been known that many different experimental models of diabetes are associated with abnormal nerve conduction. This is true for alloxan (Eliasson 1964; Eliasson, 1965; Preston, 1967; Eliasson, 1969; Sharma \& Thomas, 1974) or STZ (Sharma \& Thomas, 1974; Greene et al., 1975; Fukama et al., 1978; Jeffreys et al., 1978; Jakobsen, 1979; Sugimura et al., 1980; Weis et al., 1995) experimental diabetes. The main point that needs to be clarified is whether morphological alterations observed in the nerves and their fibers are responsible for conduction velocity impairment in experimental diabetes. This is still a controversial issue. Alterations in the peripheral nervous system of genetic or induced experimental models of diabetes have been extensively investigated and findings of relative importance and interest have been described. Nevertheless, morphological alterations totally comparable to those that occur in the human diabetic neuropathy are not completely reproducible (Sharma \& Thomas, 1999). Despite the concern that the relevance of the animals findings may be questionable, it is expected that alterations observed in experimental models, especially in the early or acute cases, will be useful for a better understanding of the neuropathy development mechanisms (Sharma \& Thomas, 1999). Controversy exists as to the morphological and morphometric changes in experimental diabetic neuropathy because the findings depend mostly on the experimental model per se, the age of the animals used on the induced models, the time-frame investigated, the nutritional state of the animals, and others.

Of all diabetic neuropathy experimental models, the rat peripheral nervous system is most commonly investigated in the literature. There is information about the neuropathy in genetic models and the alloxan model. However, the largest amount of data has been produced in the STZ-injected rat which will be primarily discussed.

In the early 70's, Sharma \& Thomas (1974) investigated the morphology of the sural, tibial fibular and abdominal vagus nerves in rats rendered diabetic with STZ injection for up to 49 weeks of survival time. The authors first investigated sciatic and tibial nerves conduction velocity before performing histological examination of the nerves. As expected, conduction velocities were smaller accordingly to the high blood glucose levels in all ages studied. Histological examination of the nerves included light and transmission electron microscopy and also measurements of myelinated fiber numbers, density, size and distribution. The results were very disappointing since no differences between controls and diabetic animals were found for each of the morphological parameters. Teased fiber preparation showed no evidence of demyelination or axonal breakdown. No alterations in the unmyelinated fibers were evident by transmission electron microscopy. Later, Jakobsen (1976a) identified in rats a reduction in the fibular nerve myelinated fiber size as early as 4 weeks after STZ injection, with no reduction in fiber number. A reduction in the myelin area was also observed with the small fibers being more affected than large ones. A study of isolated myelinated fibers (Jakobsen, 1976b) showed no signs of demyelination. The structural abnormality of the axon was demonstrated a few weeks after the STZ injection and was prevented by insulin treatment (Jakobsen, 1979). The author concluded that axonal abnormality resulted from the metabolic derangement and not from the long-term diabetic changes of intraneural vessels (Jakobsen \& Sidenius). A decrease in axonal transport of structural proteins was demonstrated 4 weeks after STZ injection (Jakobsen \& Sidenius, 1980). Afterwards, many literature reports confirmed these findings. Britland et al. (1985) and Bhoyrul et al. (1988) showed a reduction of the myelinated axonal area in the sciatic and tibial nerves of SZT-diabetic rats while Sharma et al. (1985), McCallum et al. (1986) and Sugimura et al. showed a reduction of the 
axonal caliber in the tibial and sural nerves of STZ-diabetic rats. The investigation of distal (plantar) nerves confirmed the axonal atrophy (Brown et al., 1980; Sharma et al., 1981; Chokroverty et al., 1988; Thomas et al., 1990) present in this experimental model of diabetic neuropathy. These findings added the information of a "dying back" neuropathy with breakdown of myelinated fibers in the most distal nerves with preservation of the fibers in more proximal ones (Brown et al.). Studies of the fibers size in $\mathrm{BB} / \mathrm{W}$ rats have also demonstrated reduction of axonal caliber mainly in the distal segments of the nerves (Yagihashi \& Sima, 1985; Yagihashi \& Sima, 1986; Medori et al., 1988; Harati), in accordance with the findings on the STZ model.

Most of these investigations were performed in limb nerves (motor and/or sensory) while trunk nerves are much less explored. More recently, we have investigated somatic and autonomic nerves of the trunk in the STZ-model of diabetic neuropathy. Limb nerves are more susceptible to external traumas or injuries especially when a long-term investigation is necessary. Thus, a possible association between the external injury and the induced diabetic neuropathy might introduce a bias in the interpretation of results. We demonstrated in the aortic depressor nerve of rats with acute STZ-diabetes, morphological signs of axonal atrophy of the myelinated fibers as early as 15 days after the injection (Salgado et al., 2001) which was also confirmed for chronic animals (Figure 1). A detailed morphometric investigation confirmed this morphological evidence (Fazan et al., 2006). Blood vessels were not investigated since most aortic depressor nerves do not have an endoneural vessel (Fazan et al., 1997; Fazan et al., 2001). We also investigated the phrenic nerve (Rodrigues Filho \& Fazan), the renal nerve (Sato et al., 2004) and the vagus nerve (Sato et al., 2006) of rats with chronic STZ-diabetes.

For the phrenic nerves, we demonstrated, using light microscopy morphometry, an axonal atrophy mainly on the large myelinated fibers. Transmission electron microscopy studies showed that the small myelinated fibers of phrenic nerves are severely affected in this experimental model and their alterations are closely related to the vascular damage present in these nerves (Fig. 2). It is well established that diabetic patients present basement membrane thickening, endothelial hyperplasia and luminal collapse of the endoneural vessels (Malik et al., 2005) and our observations in the STZ-model are in accordance to these findings in humans. Also, it has been suggested that small fibers are more susceptible to ischemia (Parry \& Brown, 1982) and the alterations we observed in the endoneural vessels in the STZ-induced diabetic neuropathy are severe enough to cause endoneural ischemia. Unmyelinated fibers are also injured but to a lesser extent (Fig. 2).
Harati stated that the structural microvascular abnormalities seen in diabetic neuropathy are late in occurrence being that the earliest adverse effects are generally metabolic and result from direct exposure of the nerves to glucose. The initial metabolic phase is then progressively replaced by a structural phase. Our observations in the aortic depressor nerves are in accordance with this hypothesis since the acute (15 days after STZ) finding was an axonal atrophy of the myelinated fibers, compatible to observations on the sciatic nerve of these animals (unpublished data) (Fig. 3), and the chronic (12 weeks after STZ) findings pointed towards a Schwann cell injury, since the myelination degree was being affected (Fazan et al., 2006) (Figure 1). For the phrenic nerves, the axonal atrophy was evident in the large myelinated fibers while the small ones were severely injured in close relation to the damaged endoneural vessels.

Several groups of investigators have described segmental demyelination and axonal degeneration in nerves of rats with chronic experimental diabetes (Hildebrand et al., 1968; Preston; Sahgal et al.; Powell et al., 1977; Yagihashi et al., 1979) but most used alloxan to induce diabetes. Several authors who investigated STZ-diabetes described segmental demyelination and remyelination as well as abnormalities of the paranodal myelin at a similar rate as for the control animals (Sharma \& Thomas, 1974; Sharma et al., 1981), suggesting these alterations to be more related aging (Jeronimo et al., 2008). Thomas et al. described a reduction of the myelin thickness mainly on the small myelinated fibers of the tibial nerves in chronic STZ-diabetic rats especially if the induction of diabetes was at early stages of life. At later stages, the axon size was consistently reduced in diabetic animals compared to controls. In our observations, chronic STZ-diabetes was able to cause demyelination, especially on the small fibers either on the aortic depressor nerve (Fig. 1B), or the phrenic nerve (Fig. 2Bb). However, these observations were not as important as the axonal atrophy present in these nerves. Also, in the acute animals, no signs of demyelination were present in any of the nerves we have already investigated with STZ-diabetes.

Human diabetic polyneuropathy was described in the late XVIII century and is the most common chronic complication of diabetes that remains the least understood (Andriambeloson et al., 2006). Despite the diversity of the reported clinical features, it seems that its morphological hallmark is the degeneration of the peripheral nerves. In fact, several reports on human nerve biopsies of diabetic patients demonstrate an axonal loss, greatest in distal nerves, in a multifocal way (Dyck et al., 1986; Behse et al., 1977; Dyck \& Giannini) that appear to be more severe in small fibers (Brown et al., 1976; Said et al., 1983). Unfortunately, these 

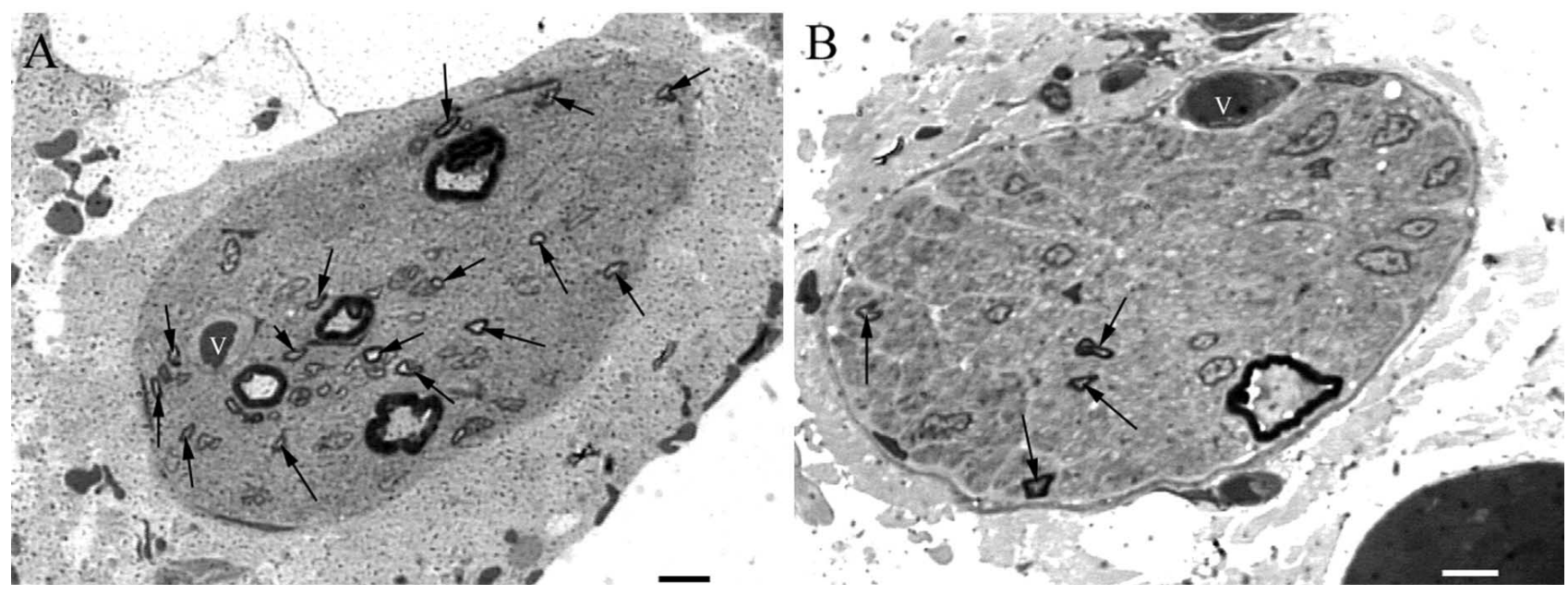

Fig. 4. Renal nerves semi-thin cross sections of control (A) and chronic STZ-diabetic (B) animals. Note the larger number of small myelinated fibers (arrows) in the control nerve compared to the diabetic one. Toluidine blue staining, scale bar $=20 \mu \mathrm{m}$.
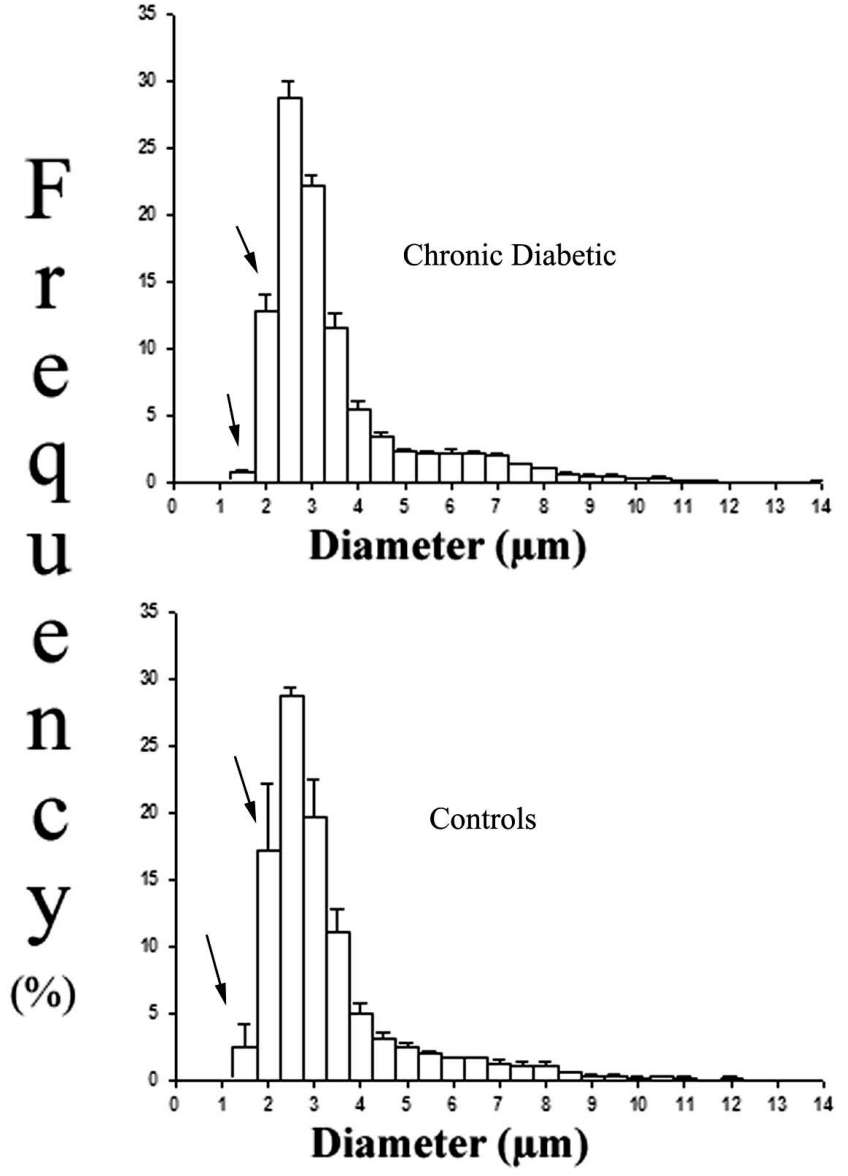

Fig. 5. Frequency distribution histograms of the myelinated fibers of the cervical vagus nerve in chronic STZ-diabetic animals (upper panel) compared to controls (lower panel). Although the shape of the distributions is very similar, note the reduction of the frequency of small myelinated fibers (arrows) on the diabetic animals' nerve. observations are not similar to most described alterations observed in experimental models of diabetes. Few experimental studies have described reduction in the number of myelinated and/or unmyelinated fibers but interestingly, most investigated autonomic nerves. Still, reports on the autonomic nervous system involvement in animal models of diabetes are rare. Yagihashi \& Sima (1985) demonstrated a decreased number of the unmyelinated fibers in the mesenteric nerves of $\mathrm{BB}$ rats after 8 months duration of diabetes. We investigated by light microscopy and morphometry the renal nerves in STZ-model of chronic diabetes and demonstrated a decrease in the small myelinated fibers number in diabetic animals (Sato et al., 2004) (Fig. 4). Later, we described a reduction in the small myelinated fiber number in the cervical vagus nerve in the same model (Sato et al., 2006), which was also demonstrated by morphometry (Fig. 5). Interestingly, we have been using the same experimental model of STZ-diabetes for a long time and had the opportunity to investigate several different nerves with intriguing findings. In somatic nerves with large myelinated fibers, axonal atrophy is the prominent alteration. On the contrary, in autonomic nerves, since there is a predominance of small myelinated and unmyelinated fibers, it seems that the main findings point towards a fiber loss. These differences between nerve alterations certainly help to explain the wide variety of signs and symptoms found in diabetic patients. Also, depending on which nerve first is most affected, patients might have predominantly sensory/motor or autonomic symptoms which is one of the most remarkable clinical characteristics of human diabetes. 


\section{Concluding Remarks}

Morphometry is a method used not only in clinical laboratory routine but also for research purposes in order to collect data, and analyze results in the most objective and precise maner. It also allows for establishing a relationship between different anatomical structures with respective functions (Fazan, 2008). Particularly for nerves, this technique is of great value as it reveals minimal morphological differences between form and function. Histologic associated with morphometric analysis is used to characterize pathological modifications at the cellular level. This is crucial for a more accurate and sensitive diagnosis of peripheral nerve diseases (Fricker et al., 2008). Three levels of analysis are generally used (Fricker et al.): (1) a global analysis of the myelination state by using teased fibers, (2) a quantitative morphometric study on semi-thin sections to quantify changes in the fiber caliber and on the myelin/ fiber ratio and (3) an electron-microscopic approach to investigate ultrastructural changes and to quantify and measure unmyelinated fibers.

Morphometry has been widely used in the investigations of human diabetic neuropathy and in experimental models of the disease, providing valuable new insights into the pathology and pathophysiology of the disease. Nerve morphometry in the STZ-model of diabetes was performed by several authors, in an attempt to duplicate and then interpret the changes that occur in early human diabetes. Thus, nerve morphometry has been a powerful tool on the investigation of the diabetic neuropathy, not only in humans, but also in experimental models.

\section{ACKNOWLEDGEMENTS}

The authors thank the excellent technical support of Mr. Antônio Renato Meirelles e Silva and Ms. Maria Cristina Lopes Schiavoni, Experimental Neurology Laboratory, Ms. Maria Tereza Maglia, Electron Microscopy Laboratory, School of Medicine of Ribeirão Preto, University of São Paulo, Mr. Sérgio Santos and Mr. Rafael Padilha, Laboratory of Immunopathology Keizo Asami, Federal University of Pernambuco and Mr. Raimundo Pimentel, FIOCRUZ, Recife, Brazil. The authors are also thankful to staff at Central Microscopy Research Facility, University of Iowa, IA, USA for the training and support during the use the JEM-1230 (JEOL) digital transmission electron microscope. CACV was a visiting scholar at the Central Microscopy Research Facility at the University of Iowa, while the study was carried out and also a recipient of a fellowship from CAPES (Coordenação de Aperfeiçoamento de Pessoal de Nível Superior). The authors appreciated the strong support from Drs. JL Lima Filho, JRM Oliveira, LC Alves, F Brayner and RCA Guedes. Grant sponsor: FAPESP (Fundação de Amparo à Pesquisa do Estado de São Paulo); Grant numbers: 04/09139-2, 0401390-8, 06/03200-7 and 06/06362-8; Grant sponsor: CNPq (Conselho Nacional de Pesquisa e Tecnologia); Grant numbers: 303802/2006-5 and 202079/2007-4.

FAZAN, S. V. P.; DE VASCONCELOS, C. C. A.; VALENÇA, M. M.; NESSLER, R. \& MOORE, K. C. Neuropatias diabéticas periféricas: una visión general morfométrica. Int. J. Morphol., 28(1):51-64, 2010.

RESUMEN: La diabetes es considerada hoy una de las principales amenazas para la salud humana en el siglo 21 y muchos investigadores se dedican a investigar la fisiopatología de la enfermedad, con otras visiones sobre el manejo de sus principales complicaciones. Dado que la comprensión de la fisiopatología de las principales complicaciones de la diabetes y sus procesos subyacentes es obligatorio, modelos experimentales de la enfermedad pueden ser útiles ya que permiten el reconocimiento de los primeros mecanismos implicados en las complicaciones a largo plazo de la diabetes. El compromiso de los nervios periféricos es muy frecuente en la diabetes mellitus y se ha documentado que un tercio de los pacientes diabéticos tiene neuropatía periférica. La prevalencia es desconocida y los informes varían de $10 \%$ a $90 \%$ en los pacientes diabéticos, en función de los criterios y métodos utilizados para definir la neuropatía. En esta revisión, se presentan los modelos experimentales más comunes de diabetes y se discuten los hallazgos patológicos en los principales nervios periféricos. Además, se destacan las visiones presentadas por la morfometría de la investigación la neuropatía diabética.

PALABRAS CLAVE: Diabetes; Modelos experimentales; Neuropatía; Morfometría.

\section{REFERENCES}

Andriambeloson, E.; Baillet, C.; Vitte, P. A.; Garotta, G.; Dreano, M. \& Callizot, N. Interleukin-6 attenuates the development of experimental diabetes-related neuropathy. Neuropathology, 26(1):32-42, 2006.
Arison, R. N.; Ciaccio, E. I.; Glitzer, M. S.; Cassaro, J. A. \& Pruss, M. P. Light and electron microscopy of lesions in rats rendered diabetic with streptozotocin. Diabetes, 16(1):51-6, 1967. 
Bailey, C. C. \& Bailey, O. T. Production of Diabetes Mellitus in Rabbits with Aloxan: Preliminary Report. JAMA, 122:1165, 1943.

Bansal, R.; Ahmad, N. \& Kidwai, J. R. Alloxan-glucose interaction: effect on incorporation of 14C-leucine into pancreatic islets of rat. Acta. Diabetol. Lat., 17(2):135-43, 1980 .

Behse, F.; Buchthal, F. \& Carlsen, F. Nerve biopsy and conduction studies in diabetic neuropathy. J. Neurol. Neurosurg. Psychiatry, 40:1072-82, 1977.

Bell, R. H. Jr. \& Hye, R. J. Animal models of diabetes mellitus: physiology and pathology. J. Surg. Res., 35(5):433-60, 1983.

Bhoyrul, S.; Sharma, A. K.; Stribling, D.; Mirrlees, D. D.; Peterson, R. G.; Farber, M. O. \& Thomas, P. K. Ultrastructural observations on myelinated fibres in experimental diabetes: effect of the aldose reductase inhibitor ponalrestat given alone or in conjunction with insulin therapy. J. Neurol. Sci., 85(2):131-47, 1988.

Boylan, J. M.; Brautigan, D. L.; Madden, J.; Raven, T.; Ellis, L. \& Gruppuso, P. A. Differential regulation of multiple hepatic protein tyrosine phosphatases in alloxan diabetic rats. J. Clin. Invest., 90(1):174-9, 1992.

Bray, G. A. \& York, D. A. Hypothalamic and genetic obesity in experimental animals: an autonomic and endocrine hypothesis. Physiol. Rev., 59(3):719-809, 1979.

Brown, M. J.; Pleasure, D. E. \& Asbury, A. K. Microdissection of peripheral nerve: collagen and lipid distribution with morphological correlation. J. Neurol. Sci., 29:361-9, 1976.

Britland, S. T.; Sharma, A. K. Duguid, I. G. \& Thomas, P. K. Ultrastructural observations on myelinated fibres in the tibial nerve of streptozotocin-diabetic rats: effect of insulin treatment. Life Support Syst., 3 Suppl 1:524-9, 1985.

Brown, M. J.; Sumner, A. J.; Greene, D. A.; Diamond, S. M. \& Asbury A. K. Distal neuropathy in experimental diabetes mellitus. Ann. Neurol., 8:168-78, 1980.

Butler, L. The inheritance of diabetes in the Chinese hamster. Diabetologia, 3:124, 1962.

Chokroverty, S.; Seiden, D.; Navidad, P. \& Cody, R. Distal axonopathy in streptozotocin diabetes in rats. Experientia, 44:444-6, 1988.

Coleman, D. L. \& Hummel, K. P. Studies with the mutation, diabetes, in the mouse. Diabetologia, 3(2):238-48, 1967.
Coleman, D. L. Obese and diabetes: two mutant genes causing diabetes-obesity syndromes in mice. Diabetologia, 14(3):141-8, 1978.

Coleman, D. L. Diabetes-obesity syndromes in mice. Diabetes, 31:1-6, 1982

Comi, G. \& Corbo, M. Metabolic neuropathies. Curr. Opin. Neurol., 11(5):523-9, 1998.

Drel, V. R.; Mashtalir. N.; Ilnytska, O.; Shin, J.; Li, F.; Lyzogubov, V. V. \& Obrosova, I. G. The leptin-deficient (ob/ob) mouse: a new animal model of peripheral neuropathy of type 2 diabetes and obesity. Diabetes, 55(12):3335-43, 2006.

Dyck, P. J.; Lais, A.; Karnes, J. L.; O'Brien, P. \& Rizza, R. Fiber loss is primary and multifocal in sural nerves in diabetic polyneuropathy. Ann. Neurol., 19:425-39, 1986.

Dyck, P. J. \& Giannini, C. Pathologic alterations in the diabetic neuropathies of humans: a review. J. Neuropathol. Exp. Neurol., 55(12):1181-93, 1996.

Dunn, J. S. \& McLetchie, N. G. B. Experimental alloxan diabetes in the rat. Lancet, 245:384-387, 1943.

Dunn, J. S.; Sheehan, H. L. \& McLetchie, N. G. B. Necrosis of islets of langerhans produced experimentally. Lancet, 244:484-487, 1943.

Eliasson, S. G. Nerve conduction changes in experimental diabetes. J. Clin. Invest., 43:2353-8, 1964.

Eliasson, S. G. Regenerative processes in experimental diabetic neuropathy. Trans. Am. Neurol. Assoc., 90:35-7, 1965.

Eliasson, S. G. Properties of isolated nerve fibres from alloxanized rats. J. Neurol. Neurosurg. Psyciatry, 32(6):5259, 1969.

Fazan, V. P.; Salgado H. C. \& Barreira, A. A. A descriptive and quantitative light and electron microscopy study of the aortic depressor nerve in normotensive rats. Hypertension, 30:6938, 1997.

Fazan, V. P.; Salgado H. C. \& Barreira, A. A. Aortic depressor nerve unmyelinated fibers in spontaneously hypertensive rats. Am. J. Physiol. Heart. Circ. Physiol., 280:H1560-4, 2001.

Fazan, V. P. S.; Ma, X.; Chapleau, M. W. \& Barreira, A. A. Qualitative and quantitative morphology of renal nerves in C57BL/6J mice. Anat. Rec., 268(4):399-404, 2002. 
Fazan, V. P. S.; Salgado, H. C. \& Barreira, A. A. Aortic depressor nerve myelinated fibers in acute and chronic experimental diabetes. Am. J. Hypertens., 19:153-160, 2006.

Fazan, V. P. S. Peripheral Nerve Morphometry. Neurobiologia (Recife), 71:99-110, 2008.

Fricker, B.; Muller, A. \& René, F. Evaluation tools and animal models of peripheral neuropathies. Neurodegener. Dis., 5:72-108, 2008.

Fukama, M.; Carpentier, J-L.; Orci, L.; Greene, D. A. \& Winegrand, A. I. An alteration in internodal myelin membrane structure in large sciatic nerve fibres in rats with acute streptozotocin diabetes and impaired nerve conduction velocity. Diabetologia, 15:65-72, 1978.

Ganda, O. P.; Rossini, A. A. \& Like, A. A. Studies on streptozotocin diabetes. Diabetes, 25(7):595-603, 1976.

Gerritsen, G. C. \& Dulin, W. E. Characterization of diabetes in the Chinese hamster. Diabetologia, 3(2):74-84, 1967.

Gerritsen, G. C.; Johnson, M. A.; Soret, M. G. \& Schultz, J. R. Epidemiology of Chinese hamsters and preliminary evidence for genetic heterogeneity of diabetes. Diabetologia, 10 Suppl:581-8, 1974.

Gerritsen, G. C. \& Blanks, M. C. Characterization of Chinese hamsters by metabolic balance, glucose tolerance and insulin secretion. Diabetologia, 10( Suppl):493-9, 1974.

Gold, G.; Reaven, G. M. \& Reaven, E. P. Effect of age on proinsulin and insulin secretory patterns in isolated rat islets. Diabetes, 30(1):77-82, 1981.

Gomori, G. \& Goldner, M. G. Production of diabetes mellitus in rats with alloxan. Proc. Soc. Exp. Biol. Med., 54:287, 1943.

Greene, D.A.; De Jesus, P. V. Jr. \& Winegrad, A. I. Effects of insulin and dietary myoinositol on impaired peripheral motor nerve conduction velocity in acute streptozotocin diabetes. J. Clin. Invest., 55(6):1326-36, 1975.

Gruppuso, P. A.; Mead, J. E. \& Fausto, N. Transforming growth factor receptors in liver regeneration following partial hepatectomy in the rat. Cancer Res., 50(5):1464-9, 1990.

Harati, Y. Diabetic peripheral neuropathies. Ann. Intern. Med., 107(4):546-59, 1987.

Harati, Y. Diabetic neuropathies: unanswered questions. Neurol. Clin., 25(1):303-17, 2007.

Herberg, L. \& Coleman, D. L. Laboratory animals exhibiting obesity and diabetes syndromes. Metabolism., 26(1):59-99, 1977.
Hildebrand, J.; Joffroy, A.; Graff, G. \& Coërs, C. Neuromuscular changes with alloxan hyperglycemia. Electrophysiological, biochemical, and histological study in rats. Arch Neurol., 18:633-41, 1968.

Hummel, K. P.; Dickie, M. M. \& Coleman, D. L. Diabetes, a new mutation in the mouse. Science, 2;153(740):1127-8, 1966.

International Diabetes Federation (IDF). Diabetes Atlas. $3^{\text {rd }}$ Ed. $19^{\text {th }}$ World Congress on Diabetes in Cape Town, South Africa Available:www.idf.org, www.eatlas.idf.org/, 2006.

Jakobsen, J. Axonal dwindling in early experimental diabetes. II. A study of isolated nerve fibres. Diabetologia, 12(6):54753, 1976a.

Jakobsen, J. Axonal dwindling in early experimental diabetes. I. A study of cross sectioned nerves. Diabetologia, 12(6):539-46, $1976 \mathrm{~b}$.

Jakobsen, J. Early and preventable changes of peripheral nerve structure and function in insulin-deficient diabetic rats. $J$. Neurol. Neurosurg. Psychiatry, 42:509-18, 1979.

Jakobsen J. \& Sidenius, P. Decreased axonal transport of structural proteins in streptozotocin diabetic rats. J. Clin. Invest., 66:292-7, 1980.

Jeffreys, J. G.; Palmano, K. P.; Sharma, A. K. \& Thomas P. K. Influence of dietary myoinositol on nerve conduction and inositol phospholipids in normal and diabetic rats. J. Neurol. Neurosurg. Psychiatry, 41:333-9, 1978.

Jeronimo, A.; Jeronimo, C. A. D.; Rodrigues Filho, O. A.; Sanada, L. S. \& Fazan, V. P. S. A morphometric study on the longitudinal and lateral symmetry of the sural nerve in mature and aging female rats. Brain Res., 1222:51-60, 2008.

Johnson, D. D. Alloxan administration in the guinea pig; a study of the regenerative phase in the islands of Langerhans. Endocrinology, 47(6):393-8, 1950.

Katsumata, K.; Katsumata, K. Jr. \& Katsumata, Y. Protective effect of diltiazem hydrochloride on the occurrence of alloxan- or streptozotocin-induced diabetes in rats. Horm. Metab. Res., 24(11):508-10, 1992.

Kurahashi, M.; Masui, H.; Yoshimoto, S.; Wakabayashi, I. \& Sakamoto, K. Effect of diethyldithiocarbamate on diabetogenic action of alloxan in rats. Diabetes Res. Clin. Pract., 19(1):39-47, 1993.

Lazarow, A. Further studies of effect of sulfur compounds on production of diabetes with alloxan. Proc. Soc. Exp. Biol. Med., 66:4-7, 1947. 
Lazarow, A. Factors controlling the development and progression of diabetes. Physiol. Rev., 29(1):48-74, 1949.

Lenzen, S. \& Munday, R. Thiol-group reactivity, hydrophilicity and stability and a comparison products and its N-methyl derivatives and a comparison with ninhydrin. Biochem. Pharmacol., 42:1385-1291, 1991.

Lenzen, S. The mechanisms of alloxan- and streptozotocininduced diabetes. Diabetologia, 51(2):216-26, 2008.

Lukens, F. D. Alloxan diabetes. Physiol. Rev., 28(3):304-30, 1948.

Malaisse, W. J.; Malaisse-Lagae, F.; Sener, A. \& Pipeleers, D. G. Determinants of the selective toxicity of alloxan to the pancreatic B cell. Proc. Natl. Acad. Sci. USA, 79(3):92730, 1982.

Malik, R. A.; Tesfaye, S.; Newrick, P. G.; Walker, D.; Rajbhandari, S. M.; Siddique, I.; Sharma, A. K.; Boulton, A. J.; King, R. H.; Thomas, P. K. \& Ward, J. D. Sural nerve pathology in diabetic patients with minimal but progressive neuropathy. Diabetologia, 48:578-85, 2005.

Makino, S.; Kunimoto, K.; Muraoka, Y.; Mizushima, Y.; Katagiri, K. \& Tochino Y. Breeding of a non-obese, diabetic strain of mice. Jikken Dobutsu, 29(1):1-13, 1980.

McCallum, K. N.; Sharma, A. K.; Blanchard, D.S.; Stribling, D.; Mirrlees, D. J.; Duguid, I. G. \& Thomas, P. K. The effect of continuous subcutaneous insulin infusion therapy on morphological and biochemical abnormalities of peripheral nerves in experimental diabetes. J. Neurol. Sci., 74(1):55-67, 1986.

Medori, R.; Jenich, H.; Autilio-Gambetti, L. \& Gambetti, P. Experimental diabetic neuropathy: similar changes of slow axonal transport and axonal size in different animal models. J. Neurosci., 8(5):1814-21, 1988.

Meier, H. \& Yerganian, G. A. Spontaneous hereditary diabetes mellitus in Chinese hamster (Cricetulus griseus). 1. Pathological findings. Proc. Soc. Exp. Biol. Med., 100(4):810-5, 1959.

Mordes, J. P. \& Rossini, A. A. Animal models of diabetes. Am. J. Med., 70(2):353-60, 1981.

Munger, B. L. \& Lang C.M. Spontaneous diabetes mellitus in guinea pigs: the acute cytopathology of the islets of Langerhans. Lab. Invest., 29(6):685-702, 1973.

Nakhouda, A. F.; Like, A. A.; Chappel, C. I.; Murray, F. T. \& Marliss, E. B. The spontaneously diabetic Wistar rat.
Metabolic and morphologic studies. Diabetes, 26(2):100$12,1977$.

Nakhouda, A. F.; Wei, C. N.; Like, A. A. \& Marliss, E. B. The spontaneously diabetic Wistar rat (the "BB" rat): the significance of transient glycosuria. Diabetes Metab., 4(4):255-9, 1978.

Parry, G. J. \& Brown, M. J. Selective fiber vulnerability in acute ischemic neuropathy. Ann. Neurol., 11:147-54, 1982.

Powell, H.; Knox, D.; Lee, S.; Charters, A. C.; Orloff, M.; Garrett, R. \& Lampert, P. Alloxan diabetic neuropathy: electron microscopic studies. Neurology, 27:60-6, 1977.

Preston, G. M. Peripheral neuropathy in the alloxan-diabetic rat. J. Physiol., 189(2):49-50, 1967.

Rakieten, N.; Rakieten, M, L. \& Nadkarni, M. V. Studies on the diabetogenic action of streptozotocin (NSC-37917). Cancer Chemother. Rep., 29:91-8, 1963.

Rerup, C. C. Drugs producing diabetes through damage of the insulin secreting cells. Pharmacol. Rev., 22(4):485-518, 1970.

Rodrigues Filho, O. A. \& Fazan, V. P. Streptozotocin induced diabetes as a model of phrenic nerve neuropathy in rats. $J$. Neurosci. Methods, 151:131-8, 2006.

Rossini, A. A.; Arcangeli, M. A. \& Cahill, G. F. Jr. Studies of alloxan toxicity on the beta cell. Diabetes, 24(5):516-22, 1975.

Sahgal, V. K.; Roy, S.; Ahuja, M. M. \& Singh, N. Diabetic neuropathy. An experimental study in alloxanised rats, with special reference to insulin therapy. Acta. Diabetol. Lat., 9:983-1006, 1972.

Salgado, H. C.; Fazan Jr.; Fazan, V. P. S.; Silva, V. J. D. \& Barreira A. A. Arterial baroreceptors and experimental diabetes. Ann. NY Acad. Sci., 940:20-27, 2001.

Said, G.; Slama, G. \& Selva, J. Progressive centripetal degeneration of axons in small fibre diabetic polyneuropathy. Brain, 106:791-807, 1983.

Sato, K. L.; Carmo, J. M. \& Fazan, V. P. S. Morfologia do Nervo Renal no Diabete Experimental Crônico em Ratos. Arquivos de Ciências da Saúde da UNIPAR, 8:69-71, 2004.

Sato, K. L.; Migliaccio, V.; Carmo, J. M.; Oliveti, M. C. D. B. B.; Ferreira, R. S. \& Fazan, V. P. S. Diabete como modelo de neuropatia autonômica. Medicina (Ribeirão Preto), 39:28-38, 2006. 
Schmidt, R. E.; Dorsey, D. A.; Beaudet, L. N.; Frederick, K. E.; Parvin, C. A.; Plurad, S. B. \& Levisetti, M.G. Non-obese diabetic mice rapidly develop dramatic sympathetic neuritic dystrophy: a new experimental model of diabetic autonomic neuropathy. Am. J. Pathol., 163(5):2077-91, 2003.

Sharma, A. K.; Bajada, S. \& Thomas, P. K. Influence of streptozotocin-induced diabetes on myelinated nerve fibre maturation and on body growth in the rat. Acta. Neuropathol., 53:257-65, 1981.

Sharma, A. K.; Duguid, I. G.; Blanchard, D. S. \& Thomas, P. K. The effect of insulin treatment on myelinated nerve fibre maturation and integrity and on body growth in streptozotocindiabetic rats. J. Neurol Sci., 67(3):285-97, 1985.

Sharma, A. K. \& Thomas, P. K. Peripheral nerve structure and function in experimental diabetes. J. Neurol. Sci., 23:1-15, 1974.

Sharma, A. K. \& Thomas, P. K. Animal models: Pathology and Pathophysiology. In: Diabetic Neuropathy. Eds Dyck, P.J. \& Thomas, P. K. $2^{\text {nd }}$ Ed. Philadelphia, W. B. Saunders Company, 1999. pp. 237-52.

Sims, E. A. \& Landau, B. R. Diabetes mellitus in the Chinese hamster. I. Metabolic and morphologic studies. Diabetologia, 3(2):115-23, 1967.

Sugimura, K.; Windebank, A. J.; Natarajan, V.; Lambert, E. H.; Schmid, H. H. \& Dyck, P. J. Interstitial hyperosmolarity may cause axis cylinder shrinkage in streptozotocin diabetic nerve. J. Neuropathol. Exp. Neurol., 39(6):710-21, 1980.

Szkudelski, T.; Kandulska, K. \& Okulicz, M. Alloxan in vivo does not only exert deleterious effects on pancreatic B cells. Physiol. Res., 47(5):343-6, 1998.

Szkudelski, T. The mechanism of alloxan and streptozotocin action in B cells of the rat pâncreas. Physiol. Res., 50(6):537-46, 2001.

Tannenbaum, G. S.; Colle, E.; Gurd, W. \& Wanamaker L. Dynamic time-course studies of the spontaneously diabetic BB Wistar rat. I. Longitudinal profiles of plasma growth hormone, insulin, and glucose. Endocrinology, 109(6):18729, 1981.

Tarui, S.; Yamada, K. \& Hanafusa, T. Animal models utilized in the research of diabetes mellitus--with special reference to insulitis-associated diabetes. Prog. Clin. Biol. Res., 229:21123, 1987.

Tiedge, M.; Lortz, S.; Drinkgern, J. \& Lenzen, S. Relation between antioxidant enzyme gene expression and antioxidative defense status of insulin-producing cells. Diabetes, 46(11):1733-42, 1997.
Thomas, P. K.; Fraher, J. P.; O'Leary, D.; Moran, M. A.; Cole, M. \& King, R. H. Relative growth and maturation of axon size and myelin thickness in the tibial nerve of the rat. 2 . Effect of streptozotocin-induced diabetes. Acta. Neuropathol., 79:375-86, 1990.

Vinik, A. I.; Park, T. S.; Stansberry, K. B. \& Pittenger, G. L. Diabetic neuropathies. Diabetologia, 43(8):957-73, 2000.

Vinik, A. I.; Maser, R. E.; Mitchell, B. D. \& Freeman, R. Diabetic autonomic neuropathy. Diabetes Care, 26(5):1553-79, 2003.

Vinik, A. I. \& Mehrabyan, A. Diabetic neuropathies. Med. Clin. N. Am., 88:947-999, 2004.

Weis, J.; Dimpfel, W. \& Schröder, J. M. Nerve conduction changes and fine structural alterations of extra- and intrafusal muscle and nerve fibers in streptozotocin diabetic rats. Muscle Nerve, 18(2):175-84, 1995.

Williams, R. \& Airey, M. Epidemiology and public health consequences of diabetes. Curr. Med. Res. Opin., 18(1):1$12,2002$.

Yagihashi, S.; Nishihira, M. \& Baba, M. Morphometrical analysis of the peripheral nerve lesions in experimental diabetes rats. Tohoku J. Exp. Med., 129:139-49, 1979.

Yagihashi, S. \& Sima A. A. Diabetic autonomic neuropathy. The distribution of structural changes in sympathetic nerves of the BB rat. Am. J. Pathol., 121(1):138-47, 1985.

Yagihashi, S. \& Sima A. A. Neuroaxonal and dendritic dystrophy in diabetic autonomic neuropathy. Classification and topographic distribution in the BB-rat. Neuropathol. Exp. Neurol., 45(5):545-65, 1986.

Zimmet, P.; Alberti, K. G. \& Shaw, J. Global and societal implications of the diabetes epidemic. Nature, 13;414(6865):782-7, 2001.

\section{Correspondence to:}

Valéria Paula Sassoli Fazan, M.D., Ph.D. Assistant Professor Department of Surgery and Anatomy,

School of Medicine of Ribeirão Preto, USP,

Av. Bandeirantes 3900, Ribeirão Preto, SP,

CEP: $14049-900$

\section{BRAZIL}

Phone: + 5516 3602-2501

FAX : + $55163633-0017$

E-mail: vpsfazan@yahoo.com.br
vpsfazan@gmail.com

Received: 08-05-2009

Accepted: 13-07-2009 